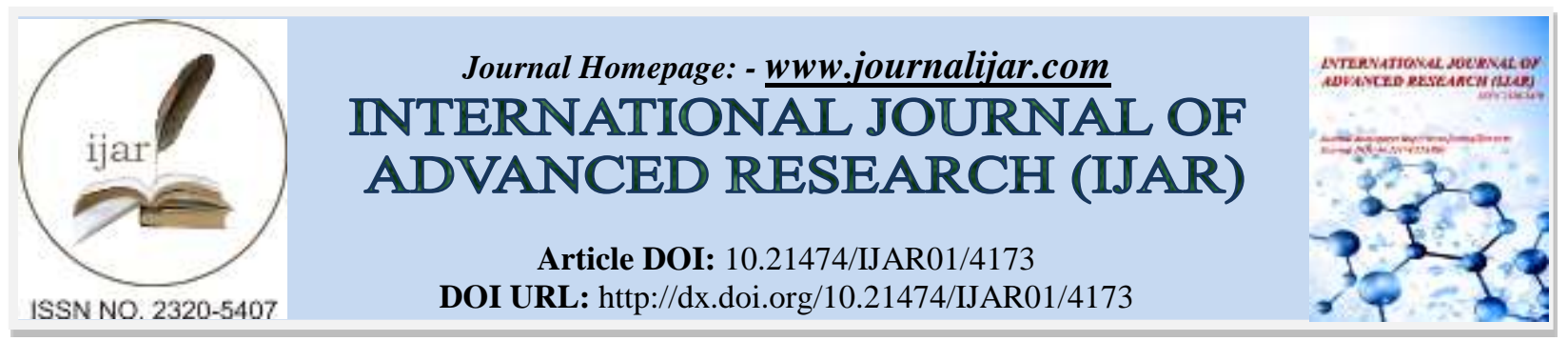

RESEARCH ARTICLE

\title{
A REVIEW ON BRAIN PLASTICITY AND FOREIGN LANGUAGE LEARNING.
}

Joo-Eun Lee.

Dep.chinese language and literature, sook-myung women's university.

\section{Manuscript Info}

Manuscript History

Received: 16 March 2017

Final Accepted: 11 April 2017

Published: May 2017

Key words:-

Brain plasticity, foreign

language learning period,

foreign language proficiency,

cognition, learning, memory.

\section{Abstract}

Neuroscientists in recent years are describing a lot of the complex structure of the brain and also the mechanisms of learning and memory in the brain by using the recently developed technology. Therefore, the researcher attempts to make a leap into an approach for a better foreign language learning by investigating the concept of brain plasticity first and followed by considering the relationship between language acquisition and learning period as well as foreign language proficiency in this paper. Also, the researcher would like to contemplate about how to engrave plasticity on the academic world and how to make best use of it.

Copy Right, IJAR, 2017,. All rights reserved.

\section{Introduction:-}

For many years, researchers tended to focus on visible and measurable behavioral evidences resulting from cognitiv e activities rather than the cognitive activities in human brain itself. Recently, cognitive science researches composin $\mathrm{g}$ of neurology and cognitive psychology are approaching systematic and deep understanding of structure and functi on of brain itself. The brain function as a mechanism of learning and memory is indeed an important and interesting subject to educators. Given the potential of cognitive science on education and considering how rapidly such potenti als can be realized just like researches on computer science, it is time to change the point of view that 'cognitive scie nce research' is meaningless in educational perspective.

Recently, cognitive scientists are discovering characteristics of brain that are different from conventional concepts of brain. That is, the human brain, which was believed to remain fixed in its structure and function after growth, has po tential for continual changes under influence of environment. This possibility was found even in elders. Also, the mo st important condition realizing this possibility is acquiring plentiful of experience in enriched environment. Cogniti ve scientists use a concept of 'brain plasticity' in relation to the idea that enriched experience can aid successful brai n development. Neurologists used recent development of technology to describe the complex structure of brain and mechanisms of learning and memory within the brain. Therefore, this study aims to explain the concept of brain plas ticity and review the relationships with language acquisition, learning period, and learning proficiency, and how brai $\mathrm{n}$ plasticity can be applied and utilized in the academia to accomplish better approach toward foreign language learni ng.

\section{Brain Plasticity:-}

Brain Plasticity of the Concept:-

Most neurologists would say that the biggest accomplishments in the field of neurology over the last two decades is 'plasticity'. One may find the term 'plasticity' as unfamiliar but it can be understood as 'possibility for change' or fl exibility. 
The traditional brain theory was some sort of 'Law of constant brain'. In short, "Brain is composed of collections of specialized processing modules where each module is developed and improved through millions of years of evolutio $\mathrm{n}$ and became genetically wired to perform only certain functions." This is so-called 'localization' theory in neurolo gy.

The neuroplasticity took the leading position in the brain science research in 21 st century. Norman Doidge introduce s numerous pioneer scientists who accomplished the revolution of plasticity. These scientists proved that human brai n can possibly change almost limitlessly using diverse animal testing.

According to Doidge, animals which received mental training or lived in enriched environment showed 5\% increase of weight in cerebral cortex and the brain region directly stimulated by the training shows up to $9 \%$ of increase of w eight. Moreover, trained or stimulated neurons put out $25 \%$ more branches resulting in increase of neuron size, num ber of connection per neuron, and blood supply. The development of neurons in aged animals is not as fast as in you ng animals. However, similar changes can be observed in aged animals as wel.

Likewise, humans can acquire brain changes through practice, stimulation, and training. "Brain Plasticity" refers to $t$ he ability of neurons to make new connection themselves, make new path in cerebral cortex, and even carry out new roles. "Neuroplasticity" means "rewiring" of brain in short. If brain can be rewired, then humans can face numerous challenges. In other words, how much effort one makes may possibly change one's life. The brain plasticity is one o $\mathrm{f}$ the biggest gift of hope provided to mankind by the science.

\section{Neurons that Fire Together, Wire Together:-}

The socialization between neurons can be described by "Neurons that fire together wire together" in neurology. Thes e tendencies of neurons serve as the physiological grounds for neuroplasticity. A Canadian psychologists named Do nald Hebb predicted the brain plasticity far before the contemporary neurologists proved it. He found that mouse rais ed at home as a pet showed higher learning ability compared to mouse raised in the lab. Based on these facts, Hebb proposed a hypothesis that learning takes place when neurons are connected and strengthened in the new manner. $\mathrm{T}$ wo neurons fire simultaneously through learning and repeated to create chemical change in both neuron strengthenin $\mathrm{g}$ their connection. The occurrence of such event for the first time increases the probability of occurrence in the futur e. This is where the famous phrase "Neurons that fire together wire together" came from.

On the other hand, the inverse of the "Neurons that fire together wire together"principle holds as well. In short, "Ne urons that fire apart wire apart" or "Neurons that don't sync don't link". The inverse principle provides neurological explanation for the learning disability and forgetfulness. The newly learned information is saved in the connection $\mathrm{p}$ atterns between neurons rather than neurons themselves.

What we call knowledge, memory, and learning are all directly connected to connections between neurons. As peopl e study and memorize, these connections strengthen. On the other hand, these connections get removed when learnin $\mathrm{g}$ and memorization stops. Once again, "Use it or lose it" is the harsh reality in the brain.

One of the most popular research topics in the neurology today is a kind of protein called brain-derived neurotrophic factor (hereafter BDNF). It helps establishment of basis for cellular circuit as well as growth and upkeep. BDNF is directly connected to "long term potentiation". The experiment showed that BDNF level increased when long term $p$ otentiation is triggered due to learning. The possibility for long term potentiation is eliminated when the protein is re moved from the brain. This experiment confirmed that chemical substances supporting learning are produced to mai ntain strong neuron connection when people study certain things intensively.

According to Doidge, humans can maintain the brain change of the young age to the old age if given with compensat ion that is large enough to continue pay attention. Learning new knowledge keeps plasticity and dopamine controllin g system from declining. The brain of Einstein was stored by an American pathology. Diamond et al. acquired small piece of Einstein's brain to analyze the composition and weight, and compared with brains of 11 normal people. Th e results showed that Einstein's brain showed 73\% more glia cells in the inferior parietal lobe in cerebral cortex.

The number of neurons in the brain increases from the early pregnancy but stops after two or three month of pregnan cy and remain constant for all life. On the other hand, the number of glia cells has to increase continuously even afte $r$ birth and the degree of increase depends on the environmental effect. The high ratio of glia cells in certain region o 
f Einstein's brain implies that Einstein conducted thinking ability that involves the area of the brain countless times $r$ esulting in continuous development of glia cells.

The observation that inferior parietal lobe in Einstein's brain is particularly developed received interests. The parieta 1 lobe synthesize all stimulations coming from different sensory organs and perceive the exterior subject by obtainin $\mathrm{g}$ relevant information from other regions of the brain. Also, this region is known to be related with forming image. According to the results of Diamond et al., Einstein's brain is thought to have extraordinary ability to come up with i mage when perceiving external stimulations. In fact, Einstein recalled that written and spoken words did not seem to play any role in his mechanism of thoughts. He felt that "combinatory play of certain signs and more or less clear i mages" seemed to be essential features in productive thoughts.

\section{Brain Plasticity and Foreign Language Learning:- \\ Brain Plasticity and Foreign Language Learning Period:- Language Acquisition:-}

People seem to go through the following stages of language learning : (1) Echoing voice composed of all possible to ne, (2) Babbling composed of phonemes characterizing the mother language, (3) One syllable word, (4) Two syllabl es word and telegraphic speech, (5) Basic structure of sentence demonstrated in adults (around age of 4). Perceptual changes of decrease in number of distinguishable phoneme and becoming more sensitive to mother language enviro nment.

Children demonstrates overextension error while learning language. This refers to the error that children extend and apply the definition of certain word to a wider scope. Human's language learning cannot be fully explained by aprior ity nor acquisition. Hypothesis testing mechanism suggests integration of apriority and acquisition. Children learn la nguage in a way that they first establish tentative hypothesis on language by their nature and test the hypothesis in ac tual environment (through upbringing process). Innate language acquisition device (LAD), which promotes languag e learning, guide children to establish such hypothesis.

Infant's ability to listen to all possible sounds when listening to people talking serves as the basis for learning any la nguage. That is, new born infants are linguistically 'all round'. Prior to learning first words, the infant's ability to dis tinguish phone of languages other than mother language decrease rapidly. At age of 12 month, infants fail to disting uish phonetic changes that they easily distinguished at age of 6 months. At the same time, infants get adopted to disti nguish sounds in their mother language. For instance, test of English pronunciation /r/ and /1/ on American infant an d Japanese infant at age of 6 month and 12 month shows surprising improvement of distinguishing $/ \mathrm{r} /$ and $/ 1 /$ pronun ciation in American infant in 8 month and 10 month whereas the ability decreased in Japanese infant. In other words, this is the period sensitive to vocal learning.

A test was conducted on American and Swedish infants who are 6 months old. The test aimed to identify whether the infants can distinguish auditory changes of typical English and Swedish vowels spoken by multiple people. These infants ignored the auditory changes that are close to their mother language. However, such 'categorical recognition' did not appear for language other than mother language. This results explains why an 11 month old Japanese infants can hardly distinguish English vowels /r/ and /l/ after experiencing Japanese. The results of brain image tests and behavioral tests on infants showed that such changes occur between 7 months and 11 months.

\section{Inborn or acquired?}

An eminent linguist, Noam Chomsky $(1965,1972)$, asserted that humans have inborn language acquisition device (L $\mathrm{AD}$ ) which promotes language acquisition. That is, we, humans, are biologically ready to learn language. The lingui stic stimulations experienced by children (spoken language or finger language) are relatively limited in terms of qua ntity and diversity. However, the internalized language structure produced by the children are highly delicate and co mplicated which makes this ability very phenomenal.

Children understand the numerous rules of the language structure implicitly, and appear to know the trick to apply $t$ he rule into new vocabularies and contexts. However, adults may learn new language if they are put into intensive fo reign language learning programs. Adult's language acquisition can be successful. However, it is still possible that a $\mathrm{n}$ accent reflecting the phonemes of the mother language. For instance, a Spanish speaker learning English will dem onstrate Spanish accent while speaking English. Likewise, an American speaking Spanish shall demonstrate Americ 
an English accent while speaking Spanish.

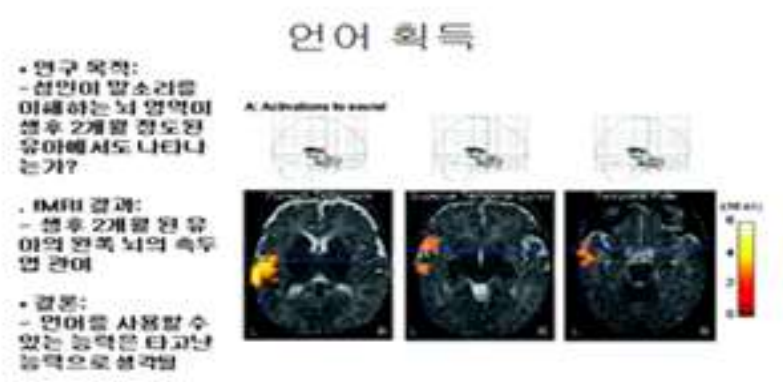

Figure 1:- Language Acquisition Language Acquisition

Research Objective:-

Does the brain region working for understanding spoken language in adults appear to be same for $\mathbf{2}$ months old infa nts?

fMRI results:

Observation on temporal lobe of left brain of 2 months old infants.

\section{Conclusion:-}

The ability to use language seems to be inborn ability.

Meta-cognition, which refers to the ability of understanding and controlling cognitive functions of oneself, provides the most outstanding assistant tool for language learning. The advantage of learning language for adults is that they a re more familiar with language structures. However, how much meta cognition contribute to learning new language depends on how closely related the newly language is with acquired language. For instance, most of English speaker $\mathrm{s}$ learn Spanish easier than Russian because the structure of Spanish is similar to English compared to Russian. In ge neral, Chinese are difficult to learn because the difference between Chinese structure and English structure is even bi gger than that of Russian.

Recently accumulating results suggest that brain can change its functional structure by itself when it is subject to eff ects due to modified environment. In other words, the environment and experience after birth affects the weight, size, and biochemical characteristics. These cognitive scientists explains that the brain damage in the early life shows cer tain degree of recovery.

In early 1970s, Peter Eimas showed that infants have exceptional ability to catching the auditory changes and disting uishing phonetic units of all languages in the world. He showed that infants can easily catch the small changes when the kind of phone change. The infants well distinguished phonetic units of languages that they never experienced. Th is phenomenon is called categorical perception. Adults possess categorical perception ability for phonetic units of la nguages that they can speak fluently. For instance, Japanese find it very difficult to differentiate $/ \mathrm{r} /$ and $/ \mathrm{l} / \mathrm{sounds}$ in American English. As we know, the both sounds are recognized as / $r$ in Japanese and Japanese speakers often get $c$ onfused with uses of the two sounds.

In 1957, behavioral psychologists B. F. Skinner suggested that language is acquired through learning. In his book titl ed $\lceil$ Verbal Behavior $\lrcorner$, he claims that language is a behavior learned in the childhood under external reinforcing a nd parental care just like other animal behaviors. Noam Chomsky who wrote criticism on $\ulcorner$ Verbal Behavior $\lrcorner$, tak e opposite view on this. Chomsky claimed that traditional reinforcement learning theory is irrelevant to the human la nguage learning. Instead, all people are inborn with 'language ability' including universal grammar and phonetics, a nd the 'selection' process begins when humans are exposed to certain languages.

Other recent studies on language acquisition of infants and children provides evidence to the idea that language acqu isition of infants are different from the ones through external reinforcement and monitoring suggested by Skinner. $\mathrm{H}$ owever, the idea claimed by Chomsky and other nativist that one process is selected from all inborn characteristics when infants experience certain language cannot provide full explanation for the characteristics of infant language a cquisition. 


\section{Does language acquisition have critical period?}

Eric Lenneburg claimed that maturation factor causes changes in the neuro-mechanism that controls language acquis ition during the adolescence. The researcher could find evidence supporting the claim from the Chinese and Korean immigrants in US who emigrated between age of 3 and 39. The immigrants were given tasks to find grammatical err ors in the sentences which are easily done by the native English speakers. The results indicated that those who emigr ated to US later showed lower scores. Similar tendencies can be found from people who learned American Sign Lan guage since birth and those who learned the sign language between age of 5 and 12 .

Then what factor restricts people from learning new language after adolescence? Development studies suggest previ ously acquired language as the factor. As a result of learning mother language, a neural commitment to understand $t$ he auditory pattern of the language occurs which degrade the ability to learn other languages in later part of life.

The deterrent effect is negligible until the neural network is completely established which is why people can easily 1 earn two or more languages when they are young. The maturity enabling learning and the neural commitment rising from learning both restrict the new language acquired at latter part of life. Humans have not completely lost the abili ty to learn new language in the later part of life. No matter when, the second language learning is improved by the $\mathrm{e}$ ducation that imitate the critical factors of the early language learning: long term auditory training under social envir onment (preoccupation), using both visual and auditory information, exposure to words similar to simplified and exa ggerated motherese.

Hubel and Weisel $(1962,1965,1970$, and 1977) are the scholars representing studies on critical period of brain deve lopments. They studied the effect of early environment deficiencies on development of cerebral cortex which proces $\mathrm{s}$ the visual information of young cats. The researchers chose 21 young cats in different ages and close one or both $o$ $\mathrm{f}$ their eyes with blindfold and let them live accordingly. The results of examination on number of cells in the same $\mathrm{r}$ egion of visual cortex are as follow:

1. The number of cells in visual cortex decreased for cats which lived blindfolded. Especially, the 4 weeks old to 5 weeks old cats were affected the most. Simply living blindfolded for short period of time, 3 to 4 days, resulted i $\mathrm{n}$ significant decrease of cells in the visual cortex.

2. The visual cortex of cats whose one eye was blindfolded for 3 months demonstrated very limited recovery durin $\mathrm{g}$ the years of growing process. The recovery refers to phenomenon that surrounding cell takes charge of the da maged function or connection with other cells increase. The results of this study proved that damage in visual fu nction in the early part of life showed far less recovery compared to damages received afterwards.

An implication from the study of Hubel and Weisel is that brain plasticity can take place not only when brain experi ences enriched environment but also when brain experiences deficient environment. It implies that the degree of rec overy from recovering experience is insignificant compared to the degree of damage, once the brain tissue and its fu nction are degenerated.

Although brain plasticity is a lifelong characteristics, it is hard to neglect the claims of numerous cognitive scientists that environmental factors at youth plays especially important role in brain development. Therefore, educators must provide children, especially the lower graders, with careful consideration, temporal and physical investments to avoi $\mathrm{d}$ deficiencies in necessary environmental experience.

Most of the researches on deficient environments so far were postmortem studies on people who experienced deficie nt environment without any choice. However, these studies have limitations such that it is hard to determine the criti cal period influenced by the deficiencies for detailed thinking abilities based on studied cases. Secondly, even if criti cal period for human brain can be found, it is hard for school to provide any support if the critical period is found to be prior to the school age. Therefore, it is important to have parents notified of the effect of environment during the critical period rather than educators in school. An important implication for educators is that plasticity characteristic $\mathrm{s}$ demonstrated in human's brain development continues after the critical period with significantly reduced effect. In this perspective, the school environment is considered to have continuous effect on home environment which is why it should be considered as subject of interest and improvement continuously. Despite being hypothetical, it is very li kely that early school environment may ply important role in the formation and development of children's thinking $f$ unction. if this is true, then richness or deficiency of early school education environment may play important role in the children's learning or realization of thinking function later. 
Brain Plasticity and Foreign Language Learning Proficiency:-

Early foreign language learner and late foreign language learner

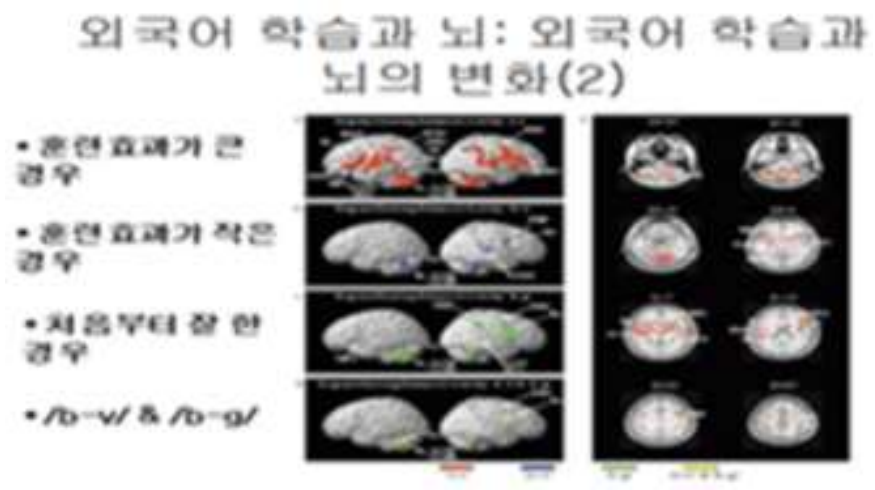

Fig.2:- Late learner and Early \& Late Learner

In order to test the difference between bilinguals who are exposed to foreign language from early period of life and $t$ hose who learned foreign language after critical period, MRI was used to measure the brain activities of study subjec ts while they were describing events that happened on previous day in both mother language and foreign language. As shown in Fig.2, the region of brain activated to mother language and language acquired at late age (front and bac k) show similar activation in Wernicke's area for both languages. However, the Boca's' area shows different sub-reg ions activated for mother language and foreign language.

\section{Can adults learn through speech sound learning?}

Age, language aptitude, and gender may be considered as factors affecting successful foreign language learning. Ho wever, perceptual factors such as awareness, attention, working memory, and information processing efficiency mus $\mathrm{t}$ be considered as well. Also, psychological and sociocultural factors like motivation for learning and sociocultural $\mathrm{b}$ ackground must be considered.

The researcher conducted distinguishing training consisting of $\mathrm{R} / \mathrm{L}, \mathrm{B} / \mathrm{V}$, and $\mathrm{B} / \mathrm{G}$ for three months in order to invest igate whether adults can learn through speech sound learning and such learning effect can be generalized. Prior to th e training, the subjects took speech sound distinguishing test. The degree of learning and generalization of the trainin $\mathrm{g}$ effect were examined after the training is completed. MRI was taken while subjects were performing speech sound distinguishing tasks. As shown in the Fig. 3, adults can learn through speech sound learning and the learning effect can be generalized. As shown in the Fig. 3, adults can learn through speech sound learning and the learning effect ca $\mathrm{n}$ be generalized.

Fig.3:- Foreign Language Learning and Brain: Foreign Language Learning and Changes in Brain

- Case with high training effect

- Case with low training effect

-Case where subjects demonstrated high language proficiency from the beginning $\cdot / \mathrm{b}-\mathrm{v} / \& / \mathrm{b}-\mathrm{g} /$

Figure 5:-Foreign Language Proficiency and Brain Identical Region
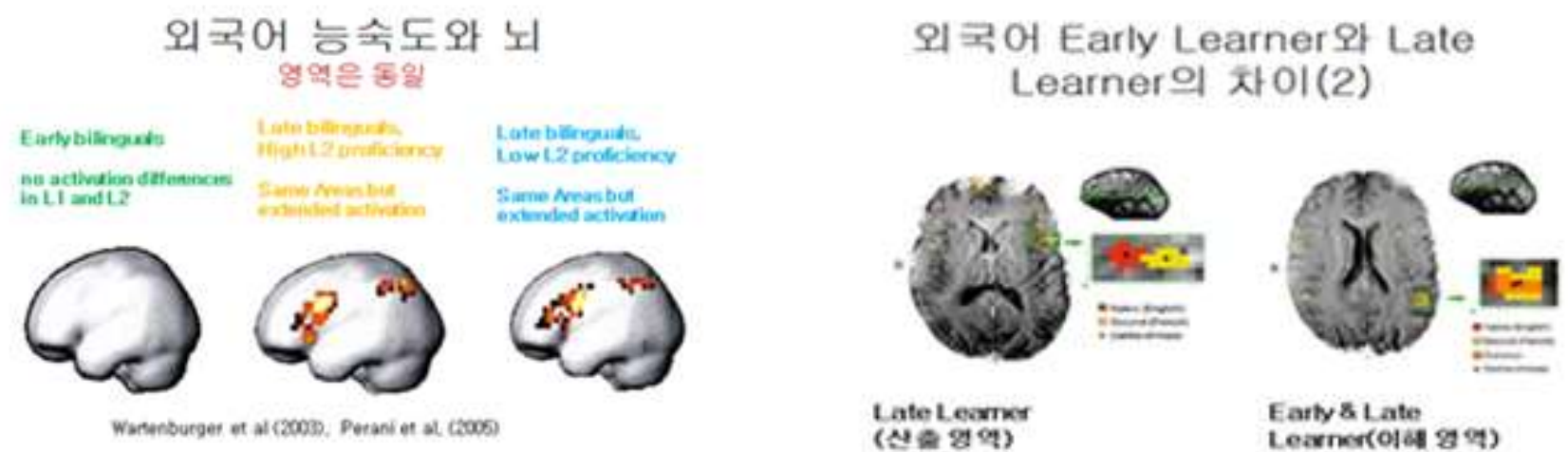

Earty 8 Late

Learner(otas 8 9 9) 
"Attention" related with memory seems to be important in learning language. The sensory memory short term memo ry via process of "attention" and the short term memory transfer to long term memory through process of "consolida tion". The foreign language is related with the memory and its utilization whereas comprehensive thoughts is related with logical firing. Perceptual abilities can be included in here. Therefore, the researcher believes that environment of learning language (ex. application of diverse teaching methods) is important as well as the existence of critical per iod for learning. Also, the efforts of learning language, that is training and repetition are very important as well. The se two factors can react complexly to create good effect. The language learning environment is very important. In fa ct, some research results indicate that diversified educational environment for children resulted in higher learning eff ect. This proves the importance of application of diverse teaching methods. The researcher believes that motivation $\mathrm{f}$ or learning plays very important role in adults whereas the early language environment is very important for children.

\section{Foreign language proficiency and brain:-}

The following brain activation size test was conducted in order to identify the relationship between foreign language proficiency and brain. First, the results of behavioral experiment on difference between less proficient L2 group (2n $\mathrm{d}$ language learner) and proficient L2 group (end language group) showed that language proficiency rather than the $\mathrm{p}$ eriod of start learning 2nd language determines the size and region of brain activation in 2nd language learner who is not an innate bilingual.

Fig.4 represents the brain activity pattern while Spanish and Catalan bilingual is searching for vocabulary. (a) Refers to brain activity pattern for bilingual with L1 (Spanish) and L2 (Catalan) whereas (b) refers to brain activity pattern for bilingual with L1 (Catalan) and L2 (Spanish). The amount necessary for Spanish to form L2 vocabulary is reduc ed compared to left cortex activation of Catalan who are less exposed to Spanish language. That is, the neural netwo rk on the left cerebral hemisphere expanded to perform less proficient 2 nd language.

Brain image studies have been attempting to answer the question whether two different languages depend on identic al brain system in consideration with selective factors. The following conclusions were made. In general, most of the studies reported that brain activation for L1 and L2 are largely overlapped (Perani \& Abutalebi) and the degree of o verlap increases more if the L2 is acquired earlier part of life (Bloch et al., 2009). In other words, there is no solid pr oof that L1 and L2 involves different brain regions. However, the brain regions corresponding to the language proce ss is different from monolinguals and depends on the age of foreign language acquisition.

Foreign language learning affects not only the brain areas activated during the task but also the actual structure of th e brain. One study compared the concentration of gray matter and white matter of the cortexes of monolinguals and bilinguals. The result showed that the concentration of gray matter in inferior parietal cortex of left hemisphere in bil inguals was higher. Also the gray matter concentration in this area was closely related with the proficiency and acqui sition age of L2.

Fig. 4:-Foreign Language Proficiency and Brain-Proficiency, and activation size are determinants L2 Retrieval with less proficiency, L2 Retrieval with more proficiency

Fig.5:-represents the different aspects of brain activity patterns while French and German bilinguals are performing grammatical tasks. These results indicate that brain activation region is expanded following the language proficiency of the 2nd language without any relation to acquisition age. That is, a frontal lobe of bilingual who is more proficien $t$ in 2nd language is more activated than that of a bilingual who is less proficient despite they both acquired 2 nd lang uage at same age. In other words, the neural commitment for mother language improves the ability to recognize prev iously learned patterns (ex. vocal learning supports vocabulary learning) but reduces ability to recognized unfamiliar patterns. The brain activation due to language learning decreases if the brain is not used repeatedly. The activation o f repeatedly used area of brain becomes easier with training and repeated learning. Therefore, it is less difficult to us e the brain while speaking the language.

\section{Conclusions:-}

The ability to manage language is similar for bilinguals who learned foreign language at early age and late language but there exists slight difference. As aforementioned, the difference in brain appears to be determined by "difference 
in proficiency in foreign language" rather than "difference in acquisition period". Therefore, adults can learn foreig $\mathrm{n}$ language well as well. Diverse teaching methods must be utilized depending on the linguistic section, contents, an $\mathrm{d}$ purpose. Also, the researcher believes that the connections between brain science, cognitive science, and psycholo gy play important role in foreign language learning and combination of theoretical aspects and experimental aspects will create significant synergy effect. Considering the neurological perspective, educational perspective (educational environment or teaching methods), and other conditions like individual efforts, the idea that foreign language learni ng is a result of linguistic knowledge but the researcher believes that it is more of integrated perspective.

Often, electrocorticography and fMRI are used to explain the changes in brain structure. In order for this researches $t$ o be continued, role of collaborators are very important as well since use of fMRI involves collaboration with hospit als and high costs. The researcher expects further studies to be conducted in these regards.

\section{References:-}

1. Kang, S. \& Nam, K. \& Lee, J (2008). Donga Science, 274, 62-77

2. Kim, S. (2004) How does brain remember. Paju: Haenamu, Mind determined by Brain, Brain determined by Mi nd

3. Nam, K. (2009) Foreign Language Learning and Change of Brain, Cognitive Neuroscience Research Laborator y, Korea University

4. Seok, Y. (2011) Novelist who stole brain, Wisdom House

5. Son, S. \& Ahn, K. (1997) A Study on Brain Functino Improvement for Creativity Improvement, Journal of Seo ul Women's University, 5, 301-315

6. Lee, K. (2000) Cognitive Linguistics, Hankookmunhwasa

7. Cho, J (1994) A Review on Implications of Brain Plasticity on Education, Educational Research, Korean Educat ional Research Association.

8. Andreas, S.(1999). Neuro-Linguistic Programing: Changing point of views. The Family Journal, 7(1), 22-28.

9. Bandler, R. \& Grinder, J. (1975). The structure of magic 1, CA : Science and Behaviour Books.

10. Bandler, R. \& Grinder, J. (1975). The structure of magic 2, CA : Science and Behaviour Books.

11. Bandler, 1985; Bandler \& Grinder, 1985; Reese, 1989; Dilts, 1990; Beaver, 1998;Phillips, 1993; McDermott \& Shircore, 1999; O'connor \& Seymour, 1994).

12. Bates, E., \& Goodman, J. (1999). On the emergence of grammar from

13. the lexicon. In B. MacWhinney (Ed.), The emergence of language.

14. Capenter, M., Nagell, K., \& Tomasello, M. (1998). Social cognition,

15. joint attention, and communicative competence from 9 to 15 months

16. of age. Monographs of the Society for Research in Child Development, 63 (4, Serial No. 255).

17. Childers, J. H.(1986). Neuro-linguistic programming in the context of group counseling. Journal for Specialists in Group Work, 11(4), 221-227.

18. Daniela Perani and Jubin Abutalebi (2005) The neural basis of first and

19. second language processing, Current Opinion in Neurobiology, 15:202-206.

20. David W. Carroll (1986) Psychology of Language. Trans. Lee, K. \& Park, H. (2009). Parkhaksa

21. Elman, J. L., Bates, E. A., Johnson, M. H., Kamiloff-Smith, A., Parisi, D., \& Plunkett, K. (1996). Rethinking in nateness: A connectionist perspective on development, Cambridge, MA: MIT Press.

22. Isabell Wartenburger1, Hauke R. Heekeren1, 2, Jubin Abutalebi3, Stefano F. Cappa3, Arno Villringer1, Daniela Perani3, Early Setting of Grammatical Processing in the Bilingual Brain, Neuron Volume 37, Issue 1, 9 Januar y 2003 , Pages $159-170$

23. Jusczyk, P. W. (1997). The discovery of spoken language. Cambridge,

24. MA: MIT Press.

25. Marie T. Banich . Rebecca J. Compton (2010) Cognitive Neuroscience Third Edition. Trans. Kim, M. et al. Par khaksa

26. O'Connor, J., \& McDermott, 1.(1996 a). Principles of NLP. New York: Thorsons Pub.

27. Robert J. Sternberg (1996). Cognitive Psychology. Trans. Kim, M. et al. (2005). Parkhaksa

28. Willis J. Edmondson, Juliane House (2000). Einführung in die Sprachlehrforschung. Trans. Shin, H. \& Lee, M (2012). Hankuk University of Foreign Studies Press. 